\title{
Abstract \\ Diagnosis of Acute Appendicitis using Alvarado Score
}

Aluvihare $\mathrm{S}^{1^{*}}$, Panditharathna $\mathrm{K}^{1}$, Dissanayake $\mathrm{S}^{1}$

${ }^{1}$ Ministry of Health Sri Lanka

\begin{abstract}
Background

Clinical diagnosis of acute appendicitis is challenging in most of the situations. Objective of the study was to evaluate the correlation between clinical presentations, laboratory investigations and the degree of the inflammation of the appendix.

\section{Method}

Forty eight patients were included ( 29 males, 19 females, age $38 \pm 24.7 \mathrm{yrs})$ in the study. Duration of the study was 6 months. Parameters were analyzed according to the Alvarado Score.

\section{Results}

Migratory Right Iliac Fossa (RIF) pain, anorexia and vomiting were recorded in $19(39.58 \%), 37(77.08 \%)$ and 22 (48.83\%) patients respectively. RIF tenderness was elicited in 41 patients $(85.42 \%)$ with rebound tenderness in 39 (81.25\%). Elevated temperature was recorded in 27 cases (56.25\%). Leucocytosis with shift to left was seen in 38 patients $(79.16 \%)$. Not inflamed and mild to moderate inflammation of appendices were noted in 8 and 26 patients respectively. Nine patients $(18.75 \%)$ had severely inflamed gangrenous appendicitis. Perforation with pus collection was recorded in 5 cases. All patients with severely inflamed and perforated appendicitis had anorexia, elevated temperature and leucocytosis ( 7 had leucocytosis $>18,000 / \mathrm{mm} 3)$. Only $3(21.42 \%)$ had initial migratory pain in that group. Nine (34.61\%) had migratory pain, $19(73.07 \%)$ had anorexia and 6 patients $(23.07 \%)$ complained of vomiting in the mild to moderately inflamed group. Out of 8 patients with negative intra-operative findings, 5 patients had an Alvarado Score of 5-7.

\section{Conclusions}

A combination of clinical and laboratory based parameters of the Alvarado score can be used as a good diagnostic work up in acute appendicitis.
\end{abstract}

Key words: Migratory right iliac fossa pain; Leucocytes; Gangrenous appendicitis

Copyright: $\odot 2015$ Aluvihare $\mathrm{S}$ et al. This is an open access article distributed under the Creative Commons Attribution License, which permits unrestricted use, distribution, and reproduction in any medium, provided the original work is properly cited.

* Correspondence : sahanaluvihare123@gmail.com

Cite this abstract as: Aluvihare S, Panditharathna K, Dissanayake S. Diagnosis of Acute Appendicitis using Alvarado Score. Anuradhapura Medical Journal 2015;9 (2Supp):S25.

DOI: http://dx.doi.org/10.4038/amj.v9i2Supp.7574 


\section{Submit your next Manuscript to}

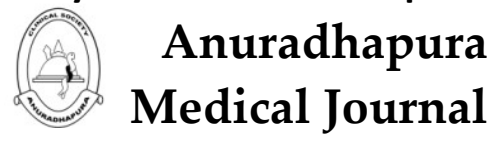

Submit your manuscript at

http://amj.sljol.info/ 